\title{
LOOKING AT THE PAST FOR A SUSTAINABLE FUTURE: WHAT ANCIENT INDIAN EDUCATION SYSTEM CAN TEACH US ABOUT EDUCATION FOR SUSTAINABLE DEVELOPMENT
}

\author{
Dr. Jyoti Parihar \\ Associate Professor, Government P.G. College of Education, \\ Jammu, India. \\ drjyotiparihar5@gmail.com
}

\begin{abstract}
Education has a primary and vital role to play in achieving sustainable development and it for this reason that the United national General Assembly adopted "Quality Education for All" as one of the Sustainable Development Goals (4) to be achieved by the year 2030. India, one of the members of the UN also resolves to achieve this goal and has therefore, formulated its own National Education Policy, 2020 to bring about a reformative transformation in the entire education system of the country. The framework of the policy is, however, pivoted on the principles and philosophy of the ancient education system that developed thousands of years ago and was instrumental in putting Indian educational institutions at the zenith for over centuries. This paper seeks to examine and compare the foundational principles of the NEP 2020 with those of ancient learning systems, discuss the similarities between the two and argues that Indian education policy needs to rely on and learn from the ancient educational practices to develop a sustainable future.
\end{abstract}

Keywords: education, sustainable development, ancient, New Education Policy

1.

INTRODUCTION

"Education, including formal education, public awareness-raising and training, is seen as a process by which people and societies can realize their full potential. Education is an indispensable prerequisite for the promotion of sustainable development and the better empowerment of people to deal with environmental and development issues."

-Agenda 21 Education has been considered to be the lynchpin of sustainable development in today's day and age. It is one of the most significant and relevant tools that can help reshape societies while at the same time transforming individual lives. It is realising this crucial role of education that Agenda 21 actively called for reorienting Education for sustainable development (UNESCO, 2018). The Sustainable Development Goals For 2030 seek to ensure quality education to all in order to achieve the two goals viz human development and raising awareness, increasing knowledge, and developing capacity of individuals around the world to play active roles in the work of the 2030 Development Agenda. Therefore, the role of education is being realised as both a standalone basic right required for the holistic development of an individuals and also as an implementation tool acting as a primary driver to achieve the other development goals. Education is significant for realising the aforementioned goals and thereby creating a sustainable world for the present and future generations. India too aims to achieve the SDG 4, "Quality Education for All" by 2030 and therefore, has been making concerted efforts in embracing the need to bring quality education, even to the last of all. A universal basic human right under the Universal Declaration of Human rights, the Right to Education has also been granted Constitutional recognition under Article 21-A of the Constitution of India. In the same vein, the Right to Education Act was also enacted in 2009 for providing free and compulsory education to children in the age group of 6-14 years of age. However, despite the many incessant efforts by the government for making education accessible to all Indian education system has been lacking in many respects. It has been often criticised as being designed in a way that neither the students take any interest in learning, nor do they learn anything relevant which will provide them hands-on knowledge that can be applied in real lives. Subjects have been compartmentalised to an extent that a student from one stream of education has miniscule knowledge about other stream, howsoever relevant may they be for leading a balanced knowledgeable life. The books are throttled with theoretical concepts with little scope for practical learning and research. The teaching methods in most of the educational institutions, especially public educational institutions are unilateral lecture-based and only focus on the theoretical aspects of the subject. Apart from this, the curriculum lacks behind in more ways than one, with the curriculum having been negligibly revised in the past few decades and has therefore, remained essentially the same since the early years following Independence (Sravan, 2015). Therefore, it is 


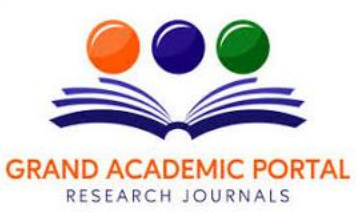
A GLOBAL JOURNAL OF HUMANITIES

( ISSN - 2581-5857)

Impact Factor: SJIF - 5.171, IIFS - 5.125

Globally peer-reviewed and open access journal.

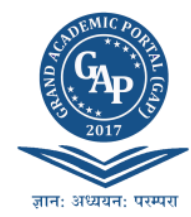

safe to say that while availability of education to all is an important milestone that we need to cross, the sort of education being available is just as important, if not more. Education, that helps one realise his/her full potential and not literacy should be the end goal of our policy It is unfortunate to note that India, the land of wonder, the abode of knowledge and wisdom, which had since the ancient times been one of the greatest seats of education worldwide, with the universities of the likes of Nalanda and Takshashila attracting students from far and wide and scholars travelling from across the seas and beyond the mountains to study at these universal centers of knowledge, is now grappling with a broken education system, with thousands of students making journeys abroad for a better education and better life. The holistic and comprehensive education policy of the Rigvedic and Buddhist times which was widely acknowledged as a source of knowledge and traditional systems that guided humanity, has in the recent past been replaced with one that focuses extensively on rote-learning and learning only for gaining marks. It is a sad state of affairs that the country that once took pride in being the seat of the greatest universities of the time like Nalanda, Takshashila and Vallabhi, today cannot even name a single institute that can compete with the present- day Oxford and Harvard. Consequently, today, as we are inching closer to a VUCA world (Volatile, Uncertain, Complex and Ambiguous), the present systems of education and the teachings they provide seem largely inadequate to the meet the challenges posed by the $21^{\text {st }}$ century world. Today, when machines and artificial intelligence (AI) are voracious eaters of jobs that were once performed by humans, the question that remains is- what next for the students passing out of our schools and colleges? Is the education being imparted to them enough to make them well- developed individuals who are understanding humans with basic skills and who can be financially independent? Or are we creating a multitude of individuals who are just literate and clueless about their future? These pressing concerns about our education system make a strong case against the present education system being in anyway sustainable and holistic. It is for this reason alone, that not a single university or college of this country finds its place in the list of top educational institutions of the world. In context of this, the question that needs to be answered is that can we bring back our lost glory as a magnanimous center of learning that we once held. Can we take our present institutions to the zenith that was once claimed by our Universities? The answer is definitely a resounding yes. The National Education Policy 2020 seeks to achieve just that. It seeks to guide the Indian education system to achieve the SDG by 2030 while at the same time driving India's ascent to become the global leader in the fields of education, economy, social justice, scientific advancement, cultural preservation and national integration (National Education Policy, 2020). The aim of the NEP is to make the Indian education system second to none by 2040, to fulfil the targets of the SDG4 and also to ensure equitable access to high quality education for all irrespective of their social or economic background. Therefore, the NEP seeks to create a better India through a better education system that is not only of high quality but also equitable and accessible. For this, the NEP realizes that the extant education system needs reformative transformation, a reconfiguration that would foster love for learning in the students at all stages of the process. To achieve such lofty goals, one would assume that the NEP would rely on new, western models of learning and teaching, the ones adopted by almost all American and European states. However, that is not the case, because in the quest to create a sustainable future through sustainable education, the NEP, very rightly, goes back to the roots, to the ancient, time-tested practices and philosophy developed over millennia. And this is exactly where the field of focus of the present research lies. The paper aims to examine how the solution for a sustainable future through the means of education lies in implementing the rich traditional value systems that formed the bedrock of the ancient system of education in India. It seeks to draw parallels between the foundational principles that drive the NEP 2020 and the principles that made the ancient Indian education system one of the bests in the world. Thereafter, it seeks to postulate that the only feasible solution for the problem of a broken education system is to adopt the methods of the ancients for a brighter future.

\section{SUSTAINABLE EDUCATION AND NEW EDUCATION POLICY 2020}

Education for sustainable development is commonly defined to mean the development of knowledge, skills, values and behaviour required to create a sustainable world. It empowers an individual to create a sustainable and developed world for herself and the future generations by equipping her with the tools of knowledge, ability, empathy, harmony, kindness, integrity. The NEP aims to fulfil the aspiration goal of making India $21^{\text {st }}$ century ready by combining the two-fulfilling the developmental goals of the country by building upon the rich cultural heritage and traditional value systems of the past. The following sections of the paper elaborate on how the NEP borrows from the ancient and traditions values and methods of education system of the country in order to address the ever-growing developmental imperatives of the country. Therefore, the policy seeks to revamp the present education system by reintroducing the foundational principles of the ancient education system, as explained below.

\section{EQUAL ACCESS TO QUALITY PRE-PRIMARY EDUCATION CATCH THEM YOUNG}

One of the fundamental areas of focus of the SDG 4 is to ensure that all children have equal access to a quality early childhood care and development, and pre-primary education to make them future ready for the upcoming 


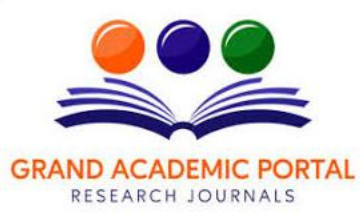
A GLOBAL JOURNAL OF HUMANITIES

( ISSN - 2581-5857)

Impact Factor: SJIF - 5.171, IIFS - 5.125

Globally peer-reviewed and open access journal.

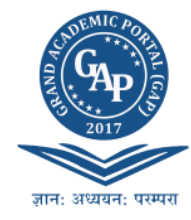

primary education, and this is enshrined in SDG 4.2. The formative years of education are of critical significance in a child's life, contributing to around 85 percent of his cumulative brain development (NEP, 2020). The care and education received during this stage of life plays a crucial and magnificent role in ensuring healthy development of an individual and transforming their lives for the better. However, the present education system has failed heavily on this parameter by not including crores of children into its fold and leaving them behind in the care in the formative stages of life. Moreover, the formal system of education for a child only began at 6 years of age thus, the potential to capture a child's mind at a young age was essentially lost by the time he/she entered school. This lacuna in the education system is sought to be filled by the NEP 2020, which stipulates that the education of a child begin quite early. The NEP 2020 seeks to provide special attention to the formative years of education i.e., 3-6 years of age. It postulates the establishment of National Curricular and Pedagogical Framework for Early Childhood Care and Education which will start from as early as possible. The policy provides for curriculum framework for as young as 0-3-year-old children and another one for 3-8-year olds. The curriculum for the toddlers and young kids would incorporate multi-faceted, play and activity-based learnings which will help in their cognitive, emotional and ethical development and also help in honing their logical, literacy and other relevant skills from a quite young age, when their minds are like fresh clay, ready to absorb the imprints that might be left on them. This is a commendable step and what makes it even more so, is the fact that this system borrows heavily from the traditional Indian system of education which has developed over millennia. Beginning formal education from the formative stages of life is an element borrowed from the traditional Rigvedic system of education under which formal education began at the age of five with a ceremony known as the Vidyarambha (Mangesh Ghonge, 2020). The ceremony was marked by the recitation of the alphabets and an ode to Goddess Sarasvati. This ceremony was open to persons of all castes thus making it inclusive and accessible to all. Under the Buddhist system of education too, widely prevalent across the length and breadth of the Indian subcontinent, education commenced at the age of eight with a ceremony called Prabrajya. After the initiation ceremony the child left his home to live in a monastery under the guidance and supervision of his preceptor. He was now referred to as a Sramana and donned a yellow robe. The remnants of these are today seen many Indian households, where still education of a child begins with the Upnayana ceremony. Under the NEP 2020 too, special focus is being laid on the Anganwadi system of education, an extant system of early childhood care for the children. Anganwadis have acted as stand-alone pre-schools for kids, especially in the rural parts of the country for decades now and to fortify their role as the same will contribute immensely to the services that they are providing. In the Anganwadi system, early child care begins around 3 years of age with the Anganwadi workers providing non-formal pre-school education to the toddlers. NEP also focusses on the creation of Balvatikas or preparatory classes for play based learning and focuses on cognitive development of the child. Education will be democratised such that its ubiquity becomes an established law and its access universal. It is widely hoped that a $79 \%$ literacy rate after 74 years of independence will be raised to $100 \%$ in five years.

\section{EQUAL ACCESS TO AFFORDABLE TECHNICAL AND VOCATIONAL EDUCATION}

SDG 4.3 aims to ensure that vocational and technical education is made accessible to all by 2030. The NEP 2020 too seeks to achieve the same and therefore, significant impetus is laid on providing the younger generation with technical and vocational skills right from the school which will help them in attaining the life skills and the technical skills required for financial success. Here too, we need to understand the roots and zenith reached in the ancient times when young men used to work an apprentice under a master for years in order to gain the expertise in the profession of their choice. Not only this, the Vedic and other texts from the ancient period mention some sixty-four arts that a person could learn and pursue. These included inter alia weaving, dyeing to manufacture of boats, art of dance, music, literature, agriculture, veterinary science, chemist and sculpting, thus, putting no limit to what a person could gain expertise in. The NEP 2020 also seeks to promulgate and propagate the concept of Lok Vidya, i.e., traditional vocational knowledge developed in India during the ancient times, made accessible to the students through vocational training.

\section{ENSURE EQUAL ACCESS TO ACQUISITION OF KNOWLEDGE AND SKILLS NEEDED TO PROMOTE SUSTAINABLE DEVELOPMENT}

Significant impetus is being given on the vocational education to gain financial independence under the SDGs. One of the most crucial strategic targets of sustainable development goal 4, therefore, is target 7 which seeks to ensure equal access to the learners in order for them to acquire the basic human skills required to lead a sustainable lifestyle and includes inter alia, values such as human rights, gender equality, promotion of a culture of peace and non-violence, global citizenship and appreciation of cultural diversity and of culture's contribution to sustainable development. To state the obvious, these skills have been a part of the ethos of the Indian heritage and Indian ancient system of education focussed on the holistic development of an individual to inculcate these values in them. The Rigvedic system of education and the consequent ones that followed it including the Buddhist schools of learning focussed from the beginning on the holistic development of an 


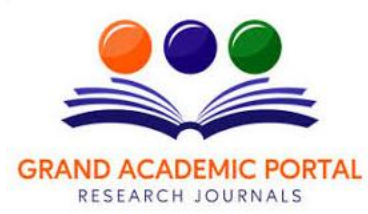
A GLOBAL JOURNAL OF HUMANITIES

( ISSN - 2581-5857)

Impact Factor: SJIF - 5.171, IIFS - 5.125

Globally peer-reviewed and open access journal.

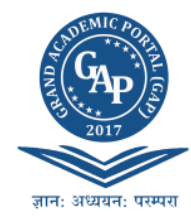

individual i.e., adequate care was taken to develop both the inner and the outer self of the student. The end goal of education in those times was never seen in terms of gaining monetary benefits, but to help students realise their conscience. Education and learning were means in the pursuit of gyan (knowledge), pragya (wisdom) and satya (truth), which were considered the highest human goal. The education emphasised on values such as humility, discipline and respect for all creatures of God (Mangesh Ghonge, 2020). And the ancient scholars and teachers realised that such a holistic development would be impossible to attain if focus was only on learning the text of the curriculum. The curriculum designing process was an independent pursuit of the teacher and was designed keeping in mind the existing needs of State and society. Also, the State had no role to play in designing the curriculum. It was wide-ranging and multi-disciplinary, consisting of the Vedas, Upanishadas, Puranas, the Vedangas including the Shiksha, Chhandas, Niruktas, Vyakarana, Jyotisha and Kalpawhile. Mastering of Vedas helped in attaining the goal of self-development and could therefore go on for as long as forty-eight years, making education itself a life-long pursuit, a journey rather than a goal. In the context of such rich curriculum, that students were taught a mix of everything-Shastras, Kavyas, Itihas, Anviksiki, Mimamsa, Shilpashastra, Arthashastra, Varta and other subjects, all having implications in the real world (Mangesh Ghonge, 2020). Physical education was given equal impetus, if not more, since the texts often mention students partaking in activities such as krida, dhanurvidya, vyayamaprakara, yogasadhana. Thus, this is a testament of how the teachers and the pupils worked together in order to make the students prolific individuals. Full emphasis was laid down on student-teacher bonding so that an everlasting relationship of trust and respect could develop between the two. These everlasting frameworks of education when modified to suit the present needs and calibrated into the modern day context would make for a sustainable model of education for comprehensive development of a student. It will also provide long-lasting and sustainable solutions to tackle present concerns in the education sector such as rote learning, lack of experiential learning or the pressing issue of brain drain.

It wouldn't be wrong to state here that NEP once again looks back into the past to build sustainable path to the future when it seeks to build upon and fortify the very same values that were the bedrock of Indian education millennia ago. It aims to ensure that learning in schools is holistic, integrated and enjoyable. The key overall thrust of curriculum and pedagogy reconfiguration across all levels of education will be to move the education system towards real understanding and towards learning and away from the culture of rote learning as is largely present today. The aim of education will not only be cognitive development, but also building character and creating holistic and well-rounded individuals equipped with the key $21^{\text {st }}$ century skills. The formative years of education would include education that is a play-based and as the years progress, education is sought to be made more multidisciplinary, exploration and experience based. Each stage of education, the preparatory, middle school and secondary stage would not be confined to fixed pigeonholes, but would rather be multidisciplinary offering greater flexibility to the students to choose the subjects of their choice. It is pertinent to note here that the ancient universities of Nalanda, Takshashila, Vallabhi and others had contributed significantly in reaching the zenith of multidisciplinary education which prepared the students not just for life after school but made them well-equipped to set on the path of complete self- realisation. Moreover, impetus is now being placed on experiential learning under the policy, which goes back to the past to bring back hands-on learning techniques such as arts-integrated and sports -integrated education, story-telling-based pedagogy, among others, as standard pedagogy within each subject, and with explorations of relations among different subjects. To close the gap in achievement of learning outcomes, classroom transactions will shift, towards competency-based learning and education. This marks a significant shift away from the present system of textbook based classroom learning and integrates the classroom with the world beyond its four walls, something that the Gurukuls and ashrams of the past had mastered to the hilt.

\section{ELIMINATE DISCRIMINATION IN EDUCATION}

This target focusses on eliminating gender discrimination in education and also by making educational institutions and education system to vulnerable people, people with disabilities and also indigenous people at all levels of education and vocational training. It is pertinent to note that NEP acknowledges the lack of access to quality education to certain vulnerable sections of our society. It takes cognizance of the fact that in our rapid quest to modernize education and make it more dynamic and digitized, we, unwittingly, left some weaker of us behind. They lagged and couldn't since then rise up to the level that many of us who are fortunate are. In context of this, and in order to achieve this target of equitable and inclusive education for all, the NEP seeks to provide equal access to the students from tribal communities, children with special needs and other socially and economically disadvantaged groups. While several efforts have been taken in the past to achieve inclusion in education, and the results too have been seen, they aren't particularly significant. The NEP therefore, focusses on providing practical solutions to the problem of exclusion. While the modern Indian education left some of our own behind, there is an urgent need to look back into the past where exclusion wasn't as serious as an issue as it is now. In ancient system of education people with special needs were not treated as ones of different kind. In ancient Gurukul system of education all children were taught together, whether they be 


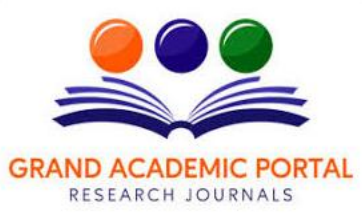

GAP BODHI TARU

A GLOBAL JOURNAL OF HUMANITIES

( ISSN - 2581-5857)

Impact Factor: SJIF - 5.171, IIFS - 5.125

Globally peer-reviewed and open access journal.

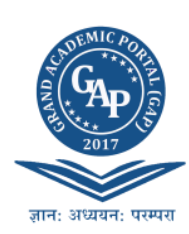

normal, gifted or having special needs. The rich cultural heritage of our country also lies in the fact that students with special learning disabilities were given an option to learn other occupations such as gardening, agriculture or household chores which could allow them to stand on their feet with ease. The ancient period saw the prevalence of ashrams and Gurukuls, residential places of learning where holistic and experiential education was provided to the students. Equal access to education was the norm of the day, with women too being educated. There were two classes of educated women, Sadyodwahas (who continued education till marriage) and Bramhavadinis (who pursued education throughout their lives and didn't marry). (Srinivas, 2013) It was due to this only that the Vedic scholars like Lopamudra, Ghosha, Geetanjali, Gargi and Apala are remembered to this day as prominent Vedic scholars.

\section{RECOMMENDATIONS AND CONCLUSION}

To develop India into a global leader into the field of education, and to bring back its universities and colleges back on the map, just like Takshashila and Nalanda once were, it is crucial to reflect into the past and adopt the fundamental principles that made these ancient centers of learning so great and magnanimous. It is a fortuitous thing that NEP 2020 seeks to do just that. In its quest to fulfil SDG 4 and attain sustainable development through education, the NEP, rather than looking for vacuous solutions and making false promises, seeks to take from the principles that were once the bedrock of the magnificent and opulent Indian education system and if such principles and methods are applied today, modified to suit the $21^{\text {st }}$ century reality, it would make the formula for a world class education system, without a doubt, and once again India would boast of universities and colleges of international excellence status. To produce the likes of Aryabhatta, Charaka, Sushruta, Chakrapani, Gargi, Panini, Patanjali and to upgrade the present education system to match the needs of today's world, it is important that the curriculum and methods of teaching be reformed as the NEP 2020 postulates to do, and in doing so, we can take significant lessons from our ancient education systems which were sustainable to the core, focused heavily on gaining insightful practical knowledge, teamwork, student- teacher relations, holistic development of the student and making them financially independent while at the same time allowing them to contribute positively to the society they are a part of. The ancient methods of teaching and learning focused on the all-round development of the learners and majority of the curriculum that was taught to the students was practical knowledge based rather than theoretical. This is one significant element that we need to aggressively adopt in the present system of education.

\section{REFERENCES}

[1] Ministry of Human Resource Development, National Education Policy 2020 (2020).

[2] Sravan, Tarang Raote, Criticisms on Education system in India, SCIT Blog < https://blog.scit.edu/2015/01/14/criticisms-on-education-systems-in-india/> (2015).

[3] S. Srinivas, Ancient Indian Education System (From the beginning to $10^{\text {th }}$ C. A.D.) Itihas, Kaleidoscope of Indian Civilisation (2013).

[4] Mangesh M. Ghonge, Rohit Bag and Aniket Singh, Indian Education: Ancient, Medieval and Modern, Education at the Intersection of Globalization and Technology (2020).

[5] UNESCO, Education for Sustainable Development and the SDGs, Policy Brief < https://en.unesco.org/sites/default/files/gap_pn1 esd_and_the_sdgs_policy_brief_ 6_page_version.pdf> (2018). 